\title{
Measuring The Benefits Of Voice-Over-Internet Protocol (VOIP)
}

Les Nunn, University of Southern Indiana, USA

Brian McGuire, University of Southern Indiana, USA

Brian Crowe, University of Southern Indiana, USA

\begin{abstract}
The following study will analyze the concept of VoIP in a business environment. It will examine the technical aspects associated with VoIP installations and the organizational structure which best facilitates the process. Furthermore, it will discuss the quantitative and non-quantitative methodologies applicable to the cost and profitability of VoIP in the business environment. Lastly, the paper will focus on recent regulation topics surrounding the new technology and provide examples of current applications.
\end{abstract}

\section{INTRODUCTION}

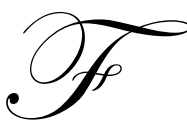

ew products since the implementation of the "world-wide web" in the mid 1990's have caused as great a commotion as that associated with "Voice-over Internet Protocol (VoIP). This four-letter abbreviation has dramatically changed the business industry and possesses the potential to alter the way business is organized and implemented in years to come. Some observers have questioned whether the technology is really worth all of the excitement, but economists have found it can generate substantial cost efficiencies.

As described by the Federal Communications Commission (FCC), "Voice over Internet Protocol (VoIP) is a technology that allows you to make voice calls using a broadband Internet connection instead of a regular (or analog) phone line." ${ }^{1}$ Telephone networks have been moving away from circuit-switched systems (hardswitch) to Internet protocol-based technology (softswitch) since 1999. However, recent technology improvements have facilitated a dramatic increase in demand for both business institutions and individual users. The number of potential customers has rapidly increased. Approximately 63 million or 22\% of Americans have broadband connections (Internet access) today. ${ }^{2}$ As a result, broadband Internet-protocol (IP) telephony subscribers increased from 114,000 as of 2003 to one million as of 2005 (a 777\% increase). ${ }^{3}$ Furthermore, search firm International Data Corporation projects business revenues from VoIP will climb to 7.6 billion dollars by $2008 .^{4}$

The following study will analyze the concept of VoIP in a business environment. It will examine the technical aspects associated with VoIP installations and the organizational structure which best facilitates the process. Furthermore, it will discuss the quantitative and non-quantitative methodologies applicable to the cost and profitability of VoIP in the business environment. Lastly, the paper will focus on recent regulation topics surrounding the new technology and provide examples of current applications.

\section{BACKGROUND/ INDUSTRY COMPOSITION}

The telecommunications industry has traveled a great distance since the first monopoly stage between 1876 and 1894 from the filing of two patents by Alexander Graham Bell and Elisha Gray. The early days of high demand and large entry barriers are over. How far have we come? As of 1999, U.S. buyers consumed approximately $\$ 200$ billion of annual telecommunication services. Local exchange revenues accounted for $\$ 100$ billion while longdistance accounted for $\$ 90$ billion. The $21^{\text {st }}$ century brought more to the world than increased gas prices and reality TV. As products evolved so did the consumer. As a result, preferences altered. While voice traffic experienced 
single-digit growth, non-voice or data traffic experienced $200 \%$ growth. ${ }^{5}$ The result; if the deviation away from the rotary phone upset your grandmother, VoIP will knock her off the rocker.

The VoIP concept has existed since the initial implementation of public Internet access. However, slow dial-up lines and poor quality of service (QoS) issues kept VoIP grounded until now. Today, many seasoned companies like AT\&T and Verizon, are actively pursuing VoIP business solutions and alternatives. ${ }^{6}$ The increase in demand, undoubtedly from the benefit of cost efficiencies and zero regulation, has many startups also pursuing market share. In the recent past, more than six VoIP startups have raised funds for research while several others are considering initial public offerings. ${ }^{7}$

Two-dozen vendors and service providers recently joined together to create a public IP infrastructure with guaranteed QoS, reliability and security. Their product is called infranet and was established as a combined effort to market inter-company peer-to-peer collaboration, utility computing and multi-provider virtual private networks (VPN). Companies involved include global service providers AOL, British Telecom, Deutsche Telecom, France Telecom, Level 3 Communications and Qwest. Network vendors include Ericsson, Juniper and Lucent. Additional computer application companies consist of HP, IBM and Oracle. ${ }^{8}$

The following chart (Exhibit One) depicts statistics in the telecommunications industry during one sample calendar year.

\begin{tabular}{|l|r|}
\multicolumn{2}{|c|}{ Exhibit One } \\
\hline \multicolumn{1}{|l|}{ Recent Statistics In The Telecommunications Industry } \\
\hline \\
\hline
\end{tabular}

In an effort to meet increased demand, telecommunication companies are forced to allocate capital to research and development. The following chart (Exhibit Two) displays how telecommunication companies allocate IT funds. 


\begin{tabular}{|c|c|}
\hline \multicolumn{2}{|c|}{$\begin{array}{c}\text { Exhibit Two } \\
\text { How Telecommunication Companies Allocate IT Funds }\end{array}$} \\
\hline Inside Telecommunication Companies & Percentage \\
\hline Average portion of revenue spent on IT & $5 \%$ \\
\hline Companies using radio-frequency identification & $0 \%$ \\
\hline Companies globally sourcing products \& supplies & $67 \%$ \\
\hline \multicolumn{2}{|l|}{ How Companies Divide Their IT Budgets } \\
\hline Hardware purchases & $13 \%$ \\
\hline IT services or outsourcing & $22 \%$ \\
\hline Research \& development & $2 \%$ \\
\hline Salaries \& benefits & $27 \%$ \\
\hline Applications & $25 \%$ \\
\hline \begin{tabular}{|l} 
Other \\
\end{tabular} & $11 \%$ \\
\hline \multicolumn{2}{|l|}{ Industry Financials } \\
\hline Average year-over-year revenue change & $-4 \%$ \\
\hline Average year-over-year net income change & $2,363 \%$ \\
\hline Data per Information Week Research & \\
\hline
\end{tabular}

\section{THE VOIP CONCEPT}

In order to understand the benefits of IP telephony, one must first comprehend the general design of public switched telephone networks (PSTN). These networks represent the ordinary telephone line found in most homes and offices. Despite its reliability and successful use, PSTN is hindered by hard line circuit switches used to connect and disconnect electronic signals. When an individual places a call over a traditional network, circuit switches establish a connection between certain logistical points which remain open throughout the duration of the call. A ten digit number is utilized in order to facilitate a specific route to the desired end point. When the call is ended the circuit closes and the call is disconnected. The user is charged based on call duration and the distance the electronic signal travels to arrive at its end point. ${ }^{9}$

The core difference between conventional lines and IP lines revolves around the use of the circuit switches. IP networks have neither a beginning nor an end point. Rather, they incorporate a continuous flow of data. As a result, the geographical location of the sender and receiver is irrelevant. Instead of hard circuits, bandwidths are utilized to carry digital signals to the desired destination. ${ }^{9}$ Voice patterns are digitized, split into data byte packets and transmitted over the Internet. Digitization allows applications to exist as a stream of numbers, which can be carried by any electronic delivery signal to a unique IP address similar to one assigned on a web page. The address allows the connection to occur and the call to transpire. ${ }^{6}$ The digitization process works the same for transmitting email and/or videos over the internet. Since the data is broken down into bytes it does not sustain the form of an analog signal (i.e. sound, text, or pictures) until it is reassembled at the termination point. ${ }^{9}$ Coders and decoders are used at both ends of the transaction for efficient bandwidth utilization. ${ }^{10}$

The technical aspect surrounding the digitalization process consists of several different components including the following: Gateway/Media Gateway, Gatekeeps, Call Agent, Media Gateway Controller, Signaling Gateway and a Call Manager. Eight protocols associated with the above components are listed below (Exhibit Three). The most popular protocol for VoIP installations is Session Initiation Protocol (SIP). It originated from the more complicated design referred to as H.328. ${ }^{10}$ 


\begin{tabular}{|c|c|c|c|}
\hline \multicolumn{3}{|c|}{$\begin{array}{c}\text { Exhibit Three } \\
\text { Eight Protocols Associated with Several Different Components }\end{array}$} & \\
\hline Type & Defined & User & \\
\hline Megaco H.328 & Gateway Control Protocol & ITU & \\
\hline MGCP & Media Gateway control Protocol & Level 3, Bellcore, Cisco, Nortel & \\
\hline RVP over IP & Remote Voice Protocol Over IP Specification & & \\
\hline SAPv2 & Session Announcement Protocol & & \\
\hline SDP & Session Description Protocol & & \\
\hline SGCP & Simple Gateway control Protocol & & \\
\hline SIP & Session Initiation Protocol & IETF & \\
\hline Skinny & Skinny Client control Protocol (SCCP) & Cisco & 10 \\
\hline
\end{tabular}

VoIP is a delay-sensitive application. As a result, QoS is checked for any delay, jitter, echo, or distortion upon the packet's arrival. The original VoIP test results concluded significant delays. Therefore, it was not until technology of the coders improved to a level in which the packets could be reassembled efficiently that the technology became popular. Delays can exist in PSTN systems; however, they are primarily due to propagation delay, which is the result of the electrical speed the signal is carried. They do not maintain the potential for longer delays generally associated with VoIP technology. Longer delays can be explained by the additional steps required under packet-based telephony. Overall distortion stems from encoding the voice signal and packet loss in the network or in the de-jittering process. These two items are broken down into four stages; packetization, transportation, de-jittering \& decoding, and mouth-to-ear contribution. ${ }^{11}$

In order to monitor the QoS, entities use a scoring method called mean opinion score (MOS). ${ }^{10}$ Although subjective, this process allows particular call monitoring which is used to grade overall service.

\section{VOIP IMPLEMENTATION ISSUES}

Businesses have few options when it comes to implementing VoIP. They can either buy IP phones and IP private branch exchanges (PBX) from equipment vendors such as Avaya, Cisco Systems, and Nortel Networks or purchase services from carriers who manage the calls from a central network. The benefit of outsourcing to carriers like AT\&T, Global Crossing, Sprint, and WorldCom remains the reduction of in-house headache implementation and maintenance woes. ${ }^{12}$ The cost per user varies per vendor. Cisco's windows based S8700 starts around $\$ 870$ per user for a 1,000-user system. Their 6700 gateway and S8300 IP PBX blades run around $\$ 1,000$ per user. ${ }^{13}$

There are a minimum of three implementation issues companies must be willing to address before diving into IP telephony. They are as follows: assessment tools, capacity utilization, and other business applications.

\section{Assessment Tools}

It remains important to maintain the ability to trouble shoot your network for potential issues. As a result, companies need to make sure their tools possess the capability to deliver granular diagnostics and reporting abilities. One tool should be able to both identify the problem as well as fix it. Experts recommend using software-based tools as opposed to hardware-based. Software tools can assess and monitor networks from one central location, rather than require on site plug in to the system. This attribute saves time and money. In addition, software updates should support advanced simulation capabilities which facilitate data traffic testing. This benefit functions to determine the maximum acceptable quality of VoIP capacity in the organization. ${ }^{14}$

Companies should monitor their MOS, which measures the amount of Mbps (a bandwidth measurement that stands for "millions of bits per second") traveling through the WAN (wide-area network) line. Additional recommendations include the following: 
- $\quad$ Call delay should not exceed 150 milliseconds.

- $\quad$ Loss should be below $1 \%$. Note: degradation can still occur with loss as low as $0.25 \%$.

- $\quad$ Traffic volume variations occur on a daily basis.

- $\quad$ Recognize the difference in voice-quality during the assessment phase can/will vary for data traffic and voice traffic. ${ }^{14}$

\section{Capacity Utilization}

Network managers must know the amount of traffic their system can handle as well as measure jitter and loss at high levels. Although obvious, these two issues are dependent on network design issues ranging in equipment and system layout. The best way to determine call capacity is to test parameters by simulating VoIP calls on the network. Only then can management truly recognize traffic potential. ${ }^{14}$ As a result, companies must be willing to provide adequate capital to properly structure the network design and provide the freedom to thoroughly test the system.

\section{Other Business Applications}

Companies should be willing to test the quality of the VoIP service throughout the entire business cycle to assess its impact on other applications. VoIP may negatively impact other IP network based systems already running on the network such as ERP (Enterprise Resource Planning system, which integrates all processes and data of an organization into one unified system) and/or Oracle systems. Furthermore, companies should be proactive in testing the impact of additional upgrades to avoid poor voice quality in the future. ${ }^{14}$ Specific ongoing monitoring techniques can include:

- $\quad$ Periodic re-assessment of tests prior to implementation which may reveal and/or reinforce trends.

- $\quad$ Maintenance of VoIP test systems including a real-time monitoring system to generate and measure short calls per hour between all locations. This aspect aids in identifying an outage or reduction in voice quality. ${ }^{15}$

\section{CONCLUSION}

Few products since the implementation of the "world-wide web" in the mid 1990's have caused as great a commotion as that associated with "Voice-over Internet Protocol (VoIP). VoIP has dramatically changed the business industry and possesses the potential to alter the way business is organized and implemented in years to come. In fact, some observers have questioned whether the technology is really worth all of the excitement, but economists have found it can generate substantial cost efficiencies.

However, VoIP may not be a perfect fit for every company. Furthermore, it may take several years before the majority of businesses drop their reliable traditional based networks; however, there is a place for VoIP in today's changing labor market.

\section{FOOTNOTES}

1. Federal Communications Commission, http://www.fcc.gov/voip, 2007

2. Owen, Thomas. "Open-Source Databases." Business 2.0. 5, (October 2004): 109.

3. "Broadband VOIP Posed for Fast Growth." Business Communications Review. 34 (July 2004): 8.

4. Senia, Al. "Ford and SBC sign VoIP deal as enterprise adoption grows." America's Network. 108 (November 2004): 8-10.

5. Kaplan, Robert S. and Cooper, Robin. Cost \& Effect. Boston: Harvard Business School Pres, 1998.

${ }^{6}$. Adams, Walter and Brock, James. The Structure of American Industry. 10 ed., New Jersey: Upper Saddle River 2001.

7. Mele, Jim. "VOIP: A Fad or the Future?" Fleet Owner. 99, (September 2004): 124-128.

8 . Thompson, Valerie. "Internet telephony takes off." The Deal.com. (April 2004): 1.

9. Schultz, Beth. "What the heck's an inFRAnet?" Network World. 21, (September 2004): 80-82. 
${ }^{10}$. Howell, Josh, Hodges, Arthur. "Telecom Regulation and Voice Over IP." Level 3 Communications unpublished position paper. Broomfield, CO, February 2004.

11. "Voice Over IP." (October 2004) < http://www.protocols.com/pbook/VoIPFamily.htm>.

12 . "All Roads Lead to IP." Computerworld. 38, (July 2004): 16B.

13. Gareiss, Robin. "Vox Popular." InformationWeek. 912, (October 2002): 39-42.

${ }^{14}$. Hochmuth, Phil. "VoIP advances". Network World. 8, (February 2002): 1-3.

${ }^{15}$. Daley, Paula, Kessel Tony. "Improve Your VOIP Deployment." Communications News. 41, (March 2004): $32-$ 36.

\section{$\underline{\text { NOTES }}$}

